\title{
Probing the release of the chronobiotic hormone melatonin from hybrid calcium alginate hydrogel beads
}

\author{
MARILENA VLACHOU ${ }^{1 *}$ \\ ANGELIKI SIAMIDI ${ }^{1}$ \\ EFSTRATIA GOULA ${ }^{1}$ \\ PANAGIOTIS GEORGAS \\ NATASSA PIPPA ${ }^{1}$ \\ VANGELIS KARALIS \\ THEODORE SENTOUKAS 2 \\ STERGIOS PISPAS ${ }^{2}$ \\ ${ }^{1}$ Section of Pharmaceutical Technology \\ Department of Pharmacy, School \\ of Health Sciences, National and \\ Kapodistrian University of Athens \\ 15784 Athens, Greece \\ ${ }^{2}$ Theoretical and Physical Chemistry \\ Institute, National Hellenic Research \\ Foundation, 11635 Athens, Greece
}

Accepted December 17, 2019

Published online January 2, 2020

\begin{abstract}
A variety of commonly used hydrogels were utilized in the preparation of calcium alginate beads, which incorporate the chronobiotic hormone melatonin (MLT). The in vitro release of the hormone in aqueous media at $\mathrm{pH} 1.2$ and 6.8 was probed in the conjunction with the swelling of the beads and their thermal degradation properties. It has been found that the release of MLT from the beads was reversibly proportional to the extent of their expansion, which depends on the molecular mass/viscosity of the biopolymers present in the beads; the higher the molecular mass/ viscosity of the hydrogels the greater the beads swelling and the less the MLT's release. Thermogravimetric analysis (TGA) data support the presence of the components in the hybrid hydrogel beads and elucidate their effects on the thermal stability of the systems. Thus, the physicochemical properties of the biopolymers used, along with their stereoelectronic features modulate the release of MLT from the beads, providing formulations able to treat sleep onset related problems or dysfunctions arising from poor sleep maintenance.
\end{abstract}

Keywords: melatonin, hydrogels, calcium alginate beads, swelling behavior, thermogravimetric analysis, in vitro release

Melatonin (N-acetyl-5-methoxytryptamine, MLT) is a hormone synthesized from the biogenic amine serotonin in the pineal gland (1). Norepinephrine also plays an important role in the production and the release of MLT, which is influenced by exposure to light (2). In addition, the necessary enzymes for the biosynthesis of MLT remain inactive in daylight and are activated during the night hours (3). The actions of MLT are associated with its binding to G-protein-coupled cell membrane receptors. So far, three different types of MLT's receptors have been characterized (MT1, MT2 and MT3) (4). MLT, a hormone involved in the regulation of the circadian rhythms, has therapeutic value in some blind subjects, restoring their disturbed circadian cycle (5). It also has a positive impact on the treatment of seasonal affective disorders (SAD), which afflict some people during the winter days (6), and it has been used to resynchronize the clock in jet-lag sufferers (7). MLT has

\footnotetext{
*Correspondence, e-mail: vlachou@pharm.uoa.gr
} 
also been implicated in a range of other diseases, including Parkinson's disease (8), Alzheimer's disease and other neurodegenerative conditions (9), and in various cancers (10). It has also been reported to be a potent antioxidant (11).

We have been interested in the development of dosage form products, which mimic the physiologically secreted high MLT levels at night, necessary to promote sleep onset and maintain sleep (12). Sleep dysfunctions, referring to sleep onset difficulties, are better treated with fast release MLT products, whilst those related to sleep maintenance problems are preferably treated with MLT modified release formulations (13-21). In this report we communicate our findings on the in vitro release of MLT from calcium alginate (CA) hydrogel beads, containing combinations of polyvinylpyrrolidone ( $\mathrm{PVP}_{10000}$ and $\left.\mathrm{PVP}_{55000}\right)$, hydroxypropylmethylcellulose $\left(\mathrm{HPMC}_{15000}\right.$ and $\left.\mathrm{HPMC}_{100000}\right)$, lactose monohydrate and as a surfactant sodium lauryl sulfate (SLS).

Beads are used for the modified release of vaccines, antibiotics, hormones and other drugs of diverse structures, as they provide large surface areas and possess an easier estimation of diffusion and mass transfer behavior. Furthermore, polymeric beads show high bioavailability and stability. Other advantages include limited fluctuation in the therapeutic range, reduced side effects, decreased dosing frequency and improved patient compliance $(21,22)$. Moreover, the swelling behavior in conditions, like those of gastrointestinal liquids, is a very important parameter that has to be investigated during the development of these systems for the oral administration of drugs (23). These compelling characteristics of the beads intrigued us to utilize them in our attempt to develop MLT formulations that can either treat sleep onset or poor sleep maintenance related problems. It was found that the higher the molecular mass/viscosity of the biopolymer, used in the construction of the beads, the higher their expansion leading to lower and prolonged MLT release. Thus, the physicochemical properties of the hydrogel used can modulate the release of MLT from the CA beads, resulting to formulations that have the potential to treat sleep onset related problems formulations (CA:PVP ${ }_{10000}, \mathrm{CA}: \mathrm{PVP}_{10000}: \mathrm{HPMC}_{15000} 1, \mathrm{CA}: \mathrm{PVP}_{55000}, \mathrm{CA}$ :Lactose and CA:PVP ${ }_{10000}:$ Lactose) and to formulations suitable for alleviating sleep maintenance dysfunctions formulations $\left(\mathrm{CA}: \mathrm{HPMC}_{15000}, \mathrm{CA}: \mathrm{PVP}_{10000}: \mathrm{HPMC}_{15000}\right.$ 2, CA:PVP ${ }_{55000}: \mathrm{HPMC}_{15000}$, CA:HPMC 100000$)$.

To the best of our knowledge, this is the first report in the literature, where CA beads and mixtures of polymers are used for the encapsulation of MLT. The prepared systems were found to be suitable for the $\mathrm{pH}$-responsive release of MLT in a manner strongly dependent on the formulation of the systems. This study could serve as a roadmap for the design and development of formulations with controlled-release properties.

\section{EXPERIMENTAL}

\section{Materials}

All of the materials were of analytical grade and used as received without further purification. In detail, $\operatorname{MLT}\left(M_{\mathrm{r}}=232.28\right.$; melting point $117^{\circ} \mathrm{C}$, solubility in water $2 \mathrm{~g} \mathrm{~L}^{-1}$ at $20{ }^{\circ} \mathrm{C}$ and $5 \mathrm{~g} \mathrm{~L}^{-1}$ at $50^{\circ} \mathrm{C}$ and octanol/water partition coefficient 1.6) was purchased from the MP Biomedicals LLC (France). Low viscosity ( $250 \mathrm{mPa} s$ of $2 \%$ solution) alginic acid sodium salt $(\mathrm{NaAlg})$ and calcium chloride dihydrate $\left(\mathrm{CaCl}_{2} \times 2 \mathrm{H}_{2} \mathrm{O}\right)$ were purchased from Sigma-Aldrich (USA). Furthermore, the simulated gastric fluid (SGF, pH 1.2) and the simu- 
lated intestinal fluid (SIF, pH 6.8) were prepared as described in the USP29-NF24 Pharmacopeia (24). Macrogol 400 (PEG 4000) was given by Fagron Hellas (Greece) and lactose monohydrate was obtained from Merck. Polyvinylpyrrolidone ( $\mathrm{PVP}_{10000}$, low $\mathrm{Mw}$ and $\mathrm{PVP}_{55000}$, high $\left.\mathrm{Mw}\right)$, hydroxypropylmethylcellulose $\left(\mathrm{HPMC}_{15000}\right.$, low $\mathrm{Mw}$ and $\mathrm{HPMC}_{100000}$, high $\mathrm{Mw}$ ) and sodium lauryl sulfate were purchased from Sigma-Aldrich. All of these materials were of analytical grade and used as received without further purification.

\section{Preparation of CA MLT beads}

MLT (2 mg) was dissolved in a solution containing 0.4 mL PEG 4000, $0.6 \mathrm{~mL} \mathrm{H}_{2} \mathrm{O}$ and $0.025 \mathrm{mg}$ of SLS, and then added to the alginate solution (vide infra).

The protocol reported by Pasparakis et al. (25), was followed for the preparation of the CA beads. Detailed experimental for the formation of the particular beads is given in the Supplementary Information file. Table I summarizes the bead compositions.

Table I. Composition of CA MLT beads

\begin{tabular}{|c|c|c|c|c|c|c|}
\hline Formulation & $\begin{array}{l}\text { MLT } \\
(\mathrm{mg})\end{array}$ & $\begin{array}{l}\mathrm{PVP}_{10000} \\
\text { (mg) }\end{array}$ & $\begin{array}{l}\text { Lactose mono- } \\
\text { hydrate (mg) }\end{array}$ & $\begin{array}{l}\mathrm{PVP}_{55000} \\
(\mathrm{mg})\end{array}$ & $\begin{array}{l}\mathrm{HPMC}_{15000} \\
\text { (mg) }\end{array}$ & $\begin{array}{l}\mathrm{HPMC}_{100000} \\
\text { (mg) }\end{array}$ \\
\hline CA/MLT & 2 & & & & & \\
\hline $\mathrm{CA} / \mathrm{PVP}_{10000}$ & 2 & 35 & & & & \\
\hline $\mathrm{CA} / \mathrm{HPMC}_{15000}$ & 2 & & & & 35 & \\
\hline $\mathrm{CA} / \mathrm{PVP}_{10000} / \mathrm{HPMC}_{15000} 1$ & 2 & 15 & & & 20 & \\
\hline $\mathrm{CA} / \mathrm{PVP}_{10000} / \mathrm{HPMC}_{15000} 2$ & 2 & 5 & & & 30 & \\
\hline $\mathrm{CA} / \mathrm{PVP}_{55000} / \mathrm{HPMC}_{15000}$ & 2 & & & 5 & 30 & \\
\hline $\mathrm{CA}: \mathrm{PVP}_{55000}$ & 2 & & & 35 & & \\
\hline CA:HPMC ${ }_{100000}$ & 2 & & & & & 35 \\
\hline CA/Lactose & 2 & & 35 & & & \\
\hline $\mathrm{CA} / \mathrm{PVP}_{10000} /$ Lactose & 2 & 17.5 & 17.5 & & & \\
\hline
\end{tabular}

\section{Thermogravimetric analysis}

A TA Instrument Q500 TGA Analyzer was utilized for the thermogravimetric analysis (TGA) experiments, in the temperature range of $30-900^{\circ} \mathrm{C}$, at a heating rate of $10^{\circ} \mathrm{C} \mathrm{min}-1$ in an air atmosphere. Dry beads were weighed directly into the TGA pan.

\section{Entrapment efficiency}

The MLT Entrapment Efficiency (EE\%) of the beads was calculated by measuring the absorbance of the supernatant solution obtained from the entrapment medium after centrifugation (Sigma 3-0KS, Germany), employing a Perkin-Elmer UV spectrophotometer 
(Norwalk, CT) at $278 \mathrm{~nm}$ and determining the EE\% from Equation 1. MLT concentration was determined from the MLT standard plot.

$$
\mathrm{EE} \%=\frac{\text { Total melatonin added }- \text { Nonentrapped melatonin }}{\text { Total melatonin added }} \times 100
$$

\section{Swelling studies and measurements}

The beads were spread on aluminum foil and dried at $40{ }^{\circ} \mathrm{C}$ overnight in an oven (WTB B34 Binder GmbH, Germany). Dry beads were used for the swelling studies. The swelling experiments were performed in two discrete dispersion media, in accordance with the reported protocols $(26,27)$. Full experimental details are given in the Supplementary Information file.

The dynamic mass change (\%) of the beads with respect to time was calculated according to Equation 2:

$$
\text { Mass change }=\frac{m_{\mathrm{t}}-m_{\mathrm{i}}}{m_{\mathrm{i}}} \times 100
$$

where $m_{\mathrm{t}}$ is the mass of the swollen beads and $m_{\mathrm{i}}$ is their initial mass.

\section{MLT release studies}

A USP XXII dissolution apparatus II (Pharma test, Germany) (paddle method) was employed for determining MLT's release from the prepared formulations. The beads were placed into two different media simulating, in subsequent order, the stomach and the enteric environment. At the end of the first phase $\left(450 \mathrm{~mL} \mathrm{HCl}\left(1 \mathrm{~mol} \mathrm{~L}^{-1}\right), \mathrm{pH} 1.2\right.$ for the first $120 \mathrm{~min})$, a solution of $450 \mathrm{~mL} \mathrm{~K}_{2} \mathrm{HPO}_{4}\left(0.14 \mathrm{~mol} \mathrm{~L}^{-1}\right)$, $\mathrm{pH}$ 9, was added to acquire the desired composition of the next phase (final volume $900 \mathrm{~mL}, \mathrm{pH}$ 6.8) and the resulting mixture was maintained at a controlled temperature of $37.0 \pm 0.5^{\circ} \mathrm{C}$. The paddles' rotation was set at $50 \mathrm{rpm}$. At each time point, the samples were removed and replaced with an equal volume of fresh medium. The concentration of MLT released into the medium was recorded using a Perkin-Elmer UV spectrophotometer (USA), at a wavelength of $278 \mathrm{~nm}$.

\section{Release kinetics}

In order to decipher the drug release mechanisms, the dissolution test results were analyzed using the Korsmeyer-Peppas equation (3):

$$
\frac{M_{\mathrm{t}}}{M_{\infty}}=k t^{n}
$$

where $M_{t} / M_{\infty}$ is the fraction of drug released at time $t, k$ is the constant related to the structural and geometric characteristic of the device, and $n$ is the release exponent, indicative of the drug release mechanism. The $k$ and $n$ values were measured up to the initial $40 \%$ release of the drug. In the case of spheres, values of $n$ between 0.43 and 0.85 are indicative of both diffusion-controlled drug release and swelling controlled drug release. Values higher than 0.85 indicate Case-II transport, which during gel swelling, is related to polymer relaxation $(28,29)$. 


\section{Statistical analysis}

In order to compare the dissolution profiles, graphs of MLT (\%) release (mean \pm SD) vs. time were produced and the Dissolution Efficiency (DE\%) (30) was calculated.

Initially, descriptive statistics were applied to the swelling and $\mathrm{DE} \%$ data. The normality of distribution was assessed using the nonparametric Shapiro-Wilk test and QQ plots. Based on these results, the parametric one-way analysis of variance (ANOVA) was applied separately to the swelling and $\mathrm{DE} \%$ data using the term 'Formulation' as a grouping factor. Post hoc tests, using the Tukey statistic, were also performed to identify potential differences between the formulations. In all analyses, the significance limit was set at $5 \%$ (i.e., $p$ $=0.05$ ). The entire analysis was implemented in IBM SPSS v.24 (IBM Corp, USA).

\section{RESULTS AND DISCUSSION}

\section{Thermogravimetric analysis}

The degradation process of CA and their hybrid analogues is depicted in Fig. 1. A certain pattern of seven degradation processes and one plateau is observed in all thermogravimetry graphs, with differences in the temperature range for each sample. The first degradation is observed in the range of $30-200^{\circ} \mathrm{C}$, which is due to the loss of physisorbed and chemisorbed water molecules. The second three-step degradation process occurs in the $190-220^{\circ} \mathrm{C}$, $220-260{ }^{\circ} \mathrm{C}$ and $260-290{ }^{\circ} \mathrm{C}$ temperature ranges resulting in a $40-45 \%$ mass loss, due to the elimination of hydroxyl groups and alginate backbone degradation (31). These procedures were slightly transposed to higher temperatures for the CA/HPMC samples. They also present two more degradation processes at the temperature range of $350-380^{\circ} \mathrm{C}$ and $380-500^{\circ} \mathrm{C}$, that are due to the melting and degradation of HPMC, respectively (32). The CA/PVP samples follow the same degradation path as the plain CA samples in the temperature range of $30-400{ }^{\circ} \mathrm{C}$. A slight differentiation for the $\mathrm{CA} / \mathrm{PVP}_{55000}$ sample is noticed in the range of $300-400{ }^{\circ} \mathrm{C}$ since it exhibits a $4 \%$ mass loss in comparison with the CA/PVP ${ }_{15000}$ sample. The

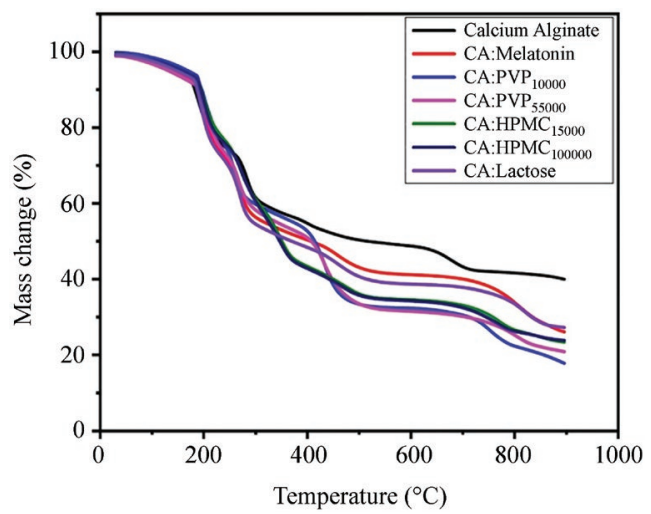

Fig. 1. Thermogravimetric analysis curves for all calcium-alginate beads (CA - calcium alginate, HPMC - hydroxypropylmethylcellulose, PVP - polyvinylpyrrolidone). The axes denote the mass change (\%) vs. temperature $\left({ }^{\circ} \mathrm{C}\right)$. 
further temperature increase in the range of $400-500{ }^{\circ} \mathrm{C}$ leads to a $20 \%$ mass loss for both CA/PVP samples, due to the full degradation of the PVP polymer (33). The CA/MLT and the $\mathrm{CA} /$ Lactose samples present a two-step process in the range of $300-500^{\circ} \mathrm{C}$, with an observed mass loss of $18 \%$ for CA/MLT and $20 \%$ for CA/Lactose respectively, depicting the decomposition of MLT and lactose (34). The final degradation process for the CA sample occurs in the region of $650-750{ }^{\circ} \mathrm{C}$ and is a result of decarboxylation and the formation of calcium oxide and calcium hydroxide (31). On the other hand, a certain hysteresis of the latter phenomenon is observed for the hybrid samples, bringing the particular process at higher temperatures of at least $50{ }^{\circ} \mathrm{C}$. More specifically, the CA/PVP ${ }_{10000}$ and the two CA/HPMC samples present the final two-step decomposition at $700{ }^{\circ} \mathrm{C}$, while the final one-step CA/MLT, $\mathrm{CA} /$ Lactose and $\mathrm{CA} / \mathrm{PVP}_{55000}$ degradation takes place at $750^{\circ} \mathrm{C}$.

\section{Entrapment efficiency of MLT beads (EE\%)}

The EE\% values obtained for all beads' formulations, containing 2 mg of MLT, were similar, as shown in Table II. In all cases the rate of EE exceeded $78 \%$, showing that the method followed for the entrapment of MLT in the beads is effective.

Table II. Entrapment of MLT in different formulations (EE\%)

\begin{tabular}{cc}
\hline Formulation & Entrapment efficiency (EE\%) \\
\hline $\mathrm{CA} / \mathrm{MLT}$ & $78.83 \pm 1.04$ \\
$\mathrm{CA} / \mathrm{PVP}_{10000}$ & $82.17 \pm 1.61$ \\
$\mathrm{CA} / \mathrm{HPMC}_{15000}$ & $78.67 \pm 1.44$ \\
$\mathrm{CA} / \mathrm{PVP}_{10000} / \mathrm{HPMC}_{15000} 1$ & $78.83 \pm 2.08$ \\
$\mathrm{CA} / \mathrm{PVP}_{10000} / \mathrm{HPMC}_{15000} 2$ & $79.00 \pm 1.32$ \\
$\mathrm{CA} / \mathrm{PVP}_{55000} / \mathrm{HPMC}_{15000}$ & $79.17 \pm 1.53$ \\
$\mathrm{CA} \mathrm{PVP}_{55000}$ & $79.50 \pm 10.50$ \\
$\mathrm{CA} / \mathrm{HPMC}_{100000}$ & $78.17 \pm 0.76$ \\
$\mathrm{CA} /$ Lactose & $79.17 \pm 1.04$ \\
$\mathrm{CA} / \mathrm{PVP}$ & $81.83 \pm 1.04$ \\
\hline
\end{tabular}

The indicated values are the mean of 3 measurements \pm SD.

\section{Swelling studies}

The swelling profile of the dry beads in SGF $(<2 \mathrm{~h})$, and in SIF, thereafter, is demonstrated in Fig. 2. The swelling of the biopolymers is presented in the graphs of mass change (\%) vs. time; the swelling was found to be dependent on the aqueous medium. The CA containing beads swell considerably in SGF $(\mathrm{pH}=1.2)$ and to a lesser extent in the SIF $(\mathrm{pH}=6.8)$ medium. The increase in the beads' mass reaches $\sim 350 \%$. This increase is due to the hydration of the carboxylic acid functional groups (35).

The descriptive statistical criteria of swelling at 180 min are listed in Table S1 in the supplementary information. Further analysis of swelling (at $180 \mathrm{~min}$ ) resulted in statistical 


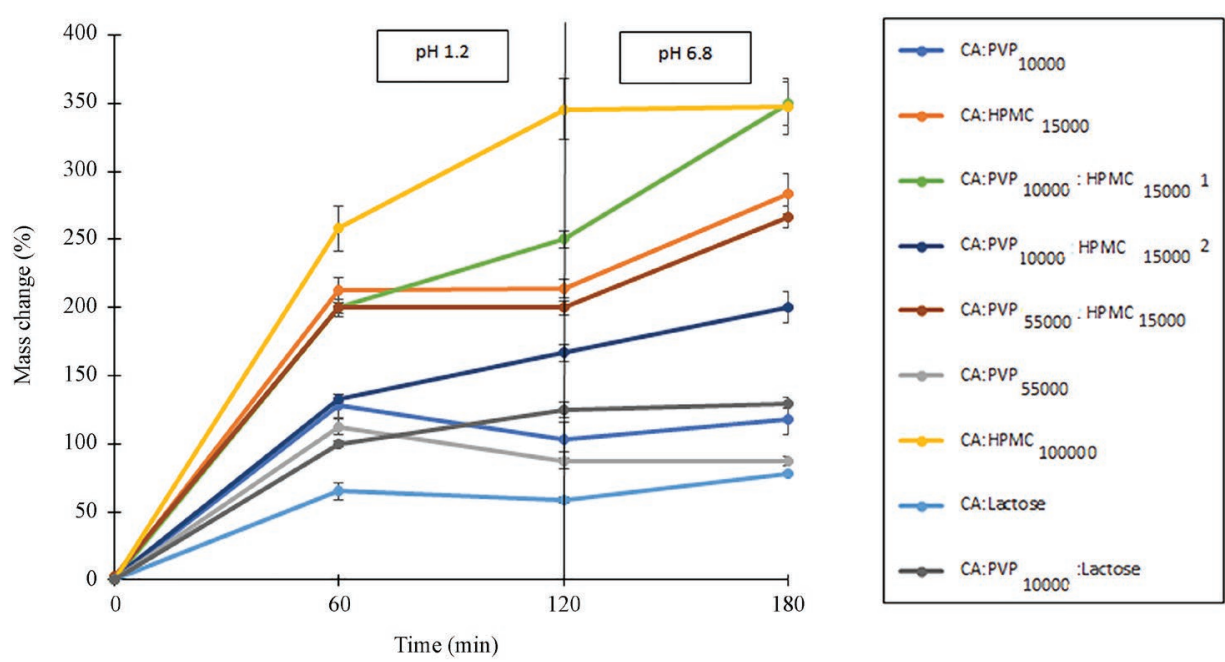

Fig. 2. Swelling profiles of dry beads at $\mathrm{pH} 1.2$ for the first two hours and at $\mathrm{pH} 6.8$, thereafter. The results denote the mean \pm S.D. $(n=3)(\mathrm{CA}$ - calcium alginate, HPMC - hydroxypropylmethylcellulose, PVP - polyvinylpyrrolidone).

significant differences $(p<0.05)$ among all pairs of formulations (Table S2) except from the following: $\mathrm{CA} / \mathrm{PVP}_{10000}$ vs. $\mathrm{CA} / \mathrm{PVP}_{55000}, \mathrm{CA} / \mathrm{PVP}_{10000}$ vs. $\mathrm{CA} / \mathrm{PVP}_{10000} /$ Lactose, CA/ $\mathrm{HPMC}_{15000}$ vs. $\mathrm{CA} / \mathrm{PVP}_{55000} / \mathrm{HPMC}_{15000}, \mathrm{CA} / \mathrm{PVP}_{10000} / \mathrm{HPMC}_{15000}$ vs. CA/HPMC 100000 , and $\mathrm{CA} / \mathrm{PVP}_{55000} / \mathrm{HPMC}_{15000}$ vs. CA/HPMC 15000 .

\section{MLT release-studies}

It is evident, from the MLT loaded hydrogel CA beads swelling data that the extent of their expansion is $\mathrm{pH}$-dependent and related to the nature and the molecular mass/viscosity of the biopolymer used (Fig. 2). Thus, the MLT beads containing $\mathrm{HPMC}_{100000}$ showed the highest swelling (formulation $\mathrm{CA} / \mathrm{HPMC}_{100000}$ ), which was followed by their congeners containing HPMC 15000 (formulation CA/HPMC ${ }_{15000}$ ). The same trend was observed, but to a lesser extent, in the case of the PVP containing MLT beads (formulation CA/PVP 55000 vs. formulation $\mathrm{CA} / \mathrm{PVP}_{10000}$ ). The lactose monohydrate MLT beads (formulation CA/Lactose) swelled less than all the above systems. It is well documented that the higher the molecular mass/viscosity of HPMC and PVP the higher their swelling due to the thicker gel they form, when in contact with aqueous media $(36,37)$.

The release of MLT from the beads was found to be reversibly proportional to the molecular mass/viscosity of the HPMC hydrogels they contain (Fig. 3). Thus, in the acidic $\mathrm{pH}$ medium, the release of MLT from the $\mathrm{HPMC}_{15000}$ beads is substantially higher (formulation $\mathrm{CA} / \mathrm{HPMC}_{15000} 97.03 \%$ at $t=120 \mathrm{~min}$ ) than the respective release from the $\mathrm{HPMC}_{100000}$ containing beads (formulation $\mathrm{CA} / \mathrm{HPMC}_{100000} 86.87 \%$ at $t=120 \mathrm{~min}$ ). A similar MLT release profile emerged and in the case of the different molecular mass/viscosity PVP containing beads (formulation $\mathrm{CA} / \mathrm{PVP}_{10000} 93.24 \%$ at $t=60 \mathrm{~min} v$ s. formulation $\mathrm{CA} / \mathrm{PVP}_{55000}$ $73.37 \%$ at $t=60 \mathrm{~min})$. At $\mathrm{pH} 6.8$, the same trend was observed in both the HPMC and PVP 


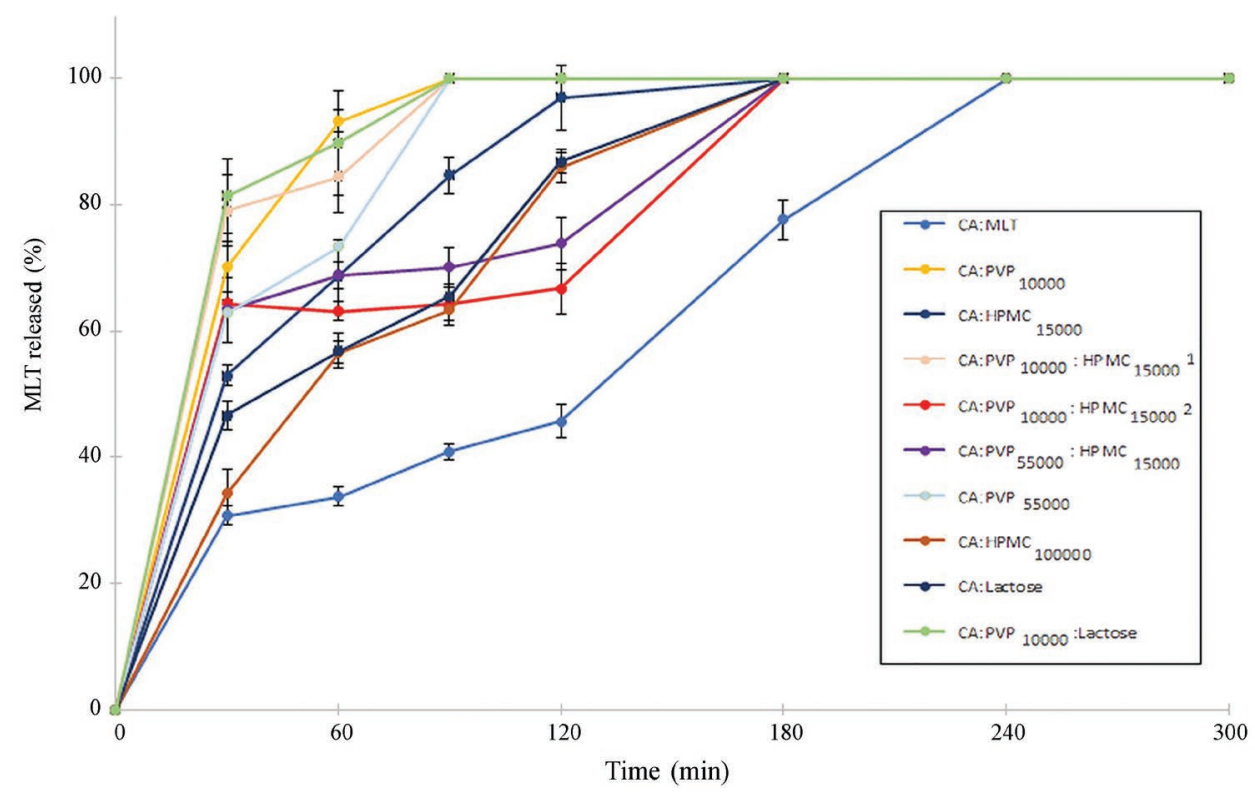

Fig. 3. In vitro MLT release from different CA beads formulations. The results denote the mean \pm S.D. $(n=3)$ (CA - calcium alginate, HPMC - hydroxypropylmethylcellulose, PVP - polyvinylpyrrolidone).

cases, but it is of no practical meaning as almost the entire amount of MLT was already released in the acidic $\mathrm{pH}$ medium, at $t \leq 120 \mathrm{~min}$.

Moreover, from the mechanistic point of view at a molecular level, and besides the influence of the extent of swelling caused by the two different types of HPMC, present in the beads, on MLT's release, the fact that a large number of $\mathrm{HPMCs} \mathrm{CH}_{2} \mathrm{OH}$ groups are methylated, reduces the ability of these hydrogels to form hydrogen bonds with MLT's C5-OMe. This results in the reduced solubility of the hormone noticed in this case.

Conversely, the facile solubilization of MLT from the PVP containing CA beads can be attributed to the conversion of PVP (II) to the gem-diol (III), at pH 1.2 (38). The hydroxyl groups of III participate in H-bond formation with MLT's C5-oxygen atom and the $\mathrm{NHCOCH}_{3}$ group, thus facilitating its aqueous solubility.

With respect to the release kinetics, it was found that the release of MLT in the case of formulations 1 and 9 followed a Fickian diffusion mechanism $(n=0.31)$. The value of the diffusion coefficient $(n=0.53)$, in the case of the $\mathrm{CA} / \mathrm{HPMC}_{100000}$ formulation, is an indication of both diffusion-controlled drug release and swelling-controlled drug release kinetics (anomalous transport). The diffusion coefficient $n$ values could not be calculated in all other cases, as the release exceeded $60 \%$, at cca $t=30 \mathrm{~min}$.

The extent of the expansion of the CA beads containing mixtures of hydrogels (formulations CA/PVP ${ }_{10000} / \mathrm{HPMC}_{15000} 1, \mathrm{CA} / \mathrm{PVP}_{10000} / \mathrm{HPMC}_{15000} 2, \mathrm{CA} / \mathrm{PVP}_{55000} / \mathrm{HPMC}_{15000}$ and $\mathrm{CA} / \mathrm{PVP}_{10000} /$ Lactose) was found to depend on the nature of the respective biopolymers and their relevant concentration in the mixtures. Thus, the least bead expansion was 
seen in the case of formulation $\mathrm{CA} / \mathrm{PVP}_{10000} /$ Lactose, where the moderately swelling promoter, lactose monohydrate, was co-present with $\mathrm{PVP}_{10000}$, in the mixture, in the same amount (17.5 mg). A high bead's expansion was noticed in the case of formulation CA/ $\mathrm{PVP}_{10000} / \mathrm{HPMC}_{15000} 2$, where $\mathrm{HPMC}_{15000}(30 \mathrm{mg})$ was mixed with a smaller amount of $\mathrm{PVP}_{10000}(5 \mathrm{mg})$. Even higher was the expansion of the beads of formulation CA/PVP 55000 / $\mathrm{HPMC}_{15000}$, as these were prepared by mixing $5 \mathrm{mg}$ of $\mathrm{PVP}_{55000}$ and $30 \mathrm{mg}$ of $\mathrm{HPMC}_{15000}$. The formulation CA/PVP $10000 / \mathrm{HPMC}_{15000} 1$, CA beads, containing $\mathrm{HPMC}_{15000}(20 \mathrm{mg})$ and $\mathrm{PVP}_{10000}(15 \mathrm{mg})$ swelled more than all the rest mixture beads composites.

Once again, the release of MLT was affected by the relevant concentration and nature of the hydrogels in the mixture. Thus, in the acidic $\mathrm{pH}$ medium the release of MLT from formulation CA/PVP $10000 / \mathrm{HPMC}_{15000} 2$ (30 mg of $\mathrm{HPMC}_{15000}$ and $5 \mathrm{mg}$ of $\left.\mathrm{PVP}_{10000}\right)$ is much lower $(66.73 \%)$ than from formulation $\mathrm{CA} / \mathrm{PVP}_{10000} / \mathrm{HPMC}_{15000} 1\left(20 \mathrm{mg} \mathrm{HPMC}_{15000}\right.$ and $\left.15 \mathrm{mg} \mathrm{PVP}_{10000}\right)$. An analogous MLT release pattern was observed in the case of formulation $\mathrm{CA} / \mathrm{PVP}_{55000} / \mathrm{HPMC}_{15000}\left(30 \mathrm{mg}\right.$ of $\mathrm{HPMC}_{15000}$ and $15 \mathrm{mg}$ of $\left.\mathrm{PVP}_{55000}\right)$. These differences in the release of MLT from mixtures of biopolymers is more profound in the case of formulation $\mathrm{CA} / \mathrm{PVP}_{10000} /$ Lactose, where MLT is entrapped in lactose monohydrate and $\mathrm{PVP}_{10000}$ constructed beads. In this case, the release of MLT reached $100 \%$ at $t=90 \mathrm{~min}$. In the $\mathrm{pH} 6.8$ medium, at $t \geq 120 \mathrm{~min}$, an analogous MLT release pattern was observed.

As it was previously mentioned, we aimed at designing and developing dosage forms, which mimic the physiologically secreted high MLT levels at night, necessary to promote sleep onset and maintain sleep. From the results obtained from the release studies, it became apparent that in all cases, MLT released from the prepared beads (40-80 \%) during the first $30 \mathrm{~min}$. This release profile is useful for the promotion of sleep. In other words, insomniacs may use the particular dosage form $30 \mathrm{~min}$ before bedtime. Moreover, the remaining MLT quantity is released within the next $3 \mathrm{~h}$, and thus these formulations are also useful in maintaining sleep.

Table $\mathrm{S} 3$ lists the descriptive statistical criteria of $\mathrm{DE} \%$. Additional statistical analysis of the $\mathrm{DE} \%$ values among the various formulations is presented in Table S4 (Supplementary Information).

\section{CONCLUSIONS}

Several hybrid CA hydrogel beads containing polymeric biomaterials and MLT as the active pharmaceutical ingredient have been produced and studied. It was shown that the right choice of common polymeric hydrogels, in terms of the nature of the polymer, its molecular mass and the composition for the preparation of CA MLT beads, determines the encapsulation and swelling properties of the hybrid beads. The successful formulations may be effectively used for treating circadian rhythm desynchronization disorders. As a result, these MLT formulations can either treat sleep onset or poor sleep maintenance related problems.

\section{REFERENCES}

1. S. M. Reppert, D. R. Weaver and C. Godson, Melatonin receptors step into the light: cloning and classification of subtypes, Trends Pharmacol. Sci. 17 (1996) 100-102; https://doi.org/10.1016/01656147(96)10005-5 
2. E. Mills, P. Wu, D. Seely and G. Guyatt, Melatonin in the treatment of cancer: a systematic review of randomized controlled trials and meta-analysis, J. Pineal. Res. 39 (2005) 360-366; https://doi. org/10.1111/j.1600-079X.2005.00258.x

3. S. Malhotra, G. Sawhney and P. Pandhi, The therapeutic potential of melatonin: a review of the science, MedGenMed. 6 (2004) 46; https://doi.org/10.0000/ncbi.nlm.nih.gov/PMC1395802

4. M. L. Dubocovich, P. Delagrange, D. N. Krause, D. Sugden, D. P. Cardinali and J. Olcese, International Union of Basic and Clinical Pharmacology. LXXV. Nomenclature, classification, and pharmacology of G protein coupled melatonin receptors, Pharmacol. Rev. 62 (2010) 343-380; https://doi. org/10.1124/pr.110.002832

5. L. M. Hack, S. W. Lockley, J. Arendt and D. J. Skene, The effects of low-dose 0.5-mg melatonin on the free-running circadian rhythms of blind subjects, J. Biol. Rhythms. 18 (2003) 420-429; https:// doi.org/10.1177/0748730403256796

6. A. J. Lewy, J. N. Rough, J. B. Songer, N. Mishra, K. Yuhas and J. S. Emens, The phase shift hypothesis for the circadian component of winter depression, Dialogues Clin. Neurosci. 9 (2007) 291-300.

7. J. Arendt and D. J. Skene, Melatonin as a chronobiotic, Sleep Med. Rev. 9 (2005) 25-39; https://doi. org/10.1016/j.smrv.2004.05.002

8. R. Sharma, C. R. McMillan, C. C. Ten and L. P. Niles, Physiological neuroprotection by melatonin in a 6-hydroxydopamine model of Parkinson's disease, Brain Res. 1068 (2006) 230-236; https://doi. org/10.1016/j.brainres.2005.10.084

9. M. Olcese, C. Cao, T. Mori, M. B. Mamcarz, A. Maxwell, M. J. Runfelt, C. Wang, X. Lin, G. Zhang and G. W. Arendash, Protection against cognitive deficits and markers of neurodegeneration by long-term oral administration of melatonin in a transgenic model of Alzheimer disease, J. Pineal Res. 47 (2009) 82-96; https://doi.org/10.1111/j.1600-079X.2009.00692.x

10. S. G. Grant, M. A. Melan, J. J. Latimer and P. A. Witt-Enderby, Melatonin and breast cancer: cellular mechanisms, clinical studies and future perspectives, Expert Rev. Mol. Med. 11 (2009) e5. https://doi.org/10.1017/S1462399409000982

11. S. Sibel, Melatonin and synthetic analogs as antioxidants, Curr. Drug Deliv. 10 (2013) 71-75; https:// doi.org/ 10.2174/1567201811310010013

12. M. Vlachou and A. Siamidi, Melatonin Modified Release Formulations, in Melatonin-Molecular Biology, Clinical and Pharmaceutical Approaches (Ed. C. M. Dragoi); http://dx.doi.org/10.5772/intechopen.78337

13. M. Vlachou, A. Siamidi, I. Pareli, A. Zampakola and S. Konstantinidou, An account of modified release of melatonin from compression-coated, uncoated and bilayer tablets, J. Pharm. Pharm. Scien. 1 (2016) 10-14; https://doi.org/ 10.24218/vjpps.2016.19

14. M. Vlachou, A. Siamidi, S. Konstantinidou and Y. Dotsikas, Optimization of controlled release matrix formulation of melatonin via experimental design, J. Pharm. Drug Deliv. Res. 5 (2016) 1-5; https://doi.org/10.4172/2325-9604.1000159

15. A. Zampakola, A. Siamidi, N. Pippa, C. Demetzos and M. Vlachou, Chronobiotic hormone melatonin: comparative in vitro release studies from matrix tablets and liposomal formulations, Lett. Drug Des. Discov. 14 (2017) 476-480; https://doi.org/10.2174/1570180813666161006162246

16. M. Vlachou, M. Papamichael, A. Siamidi, I. Fragouli, P. A. Afroudakis, R. Kompogennitaki and Y. Dotsikas, Comparative in vitro controlled release studies on the chronobiotic hormone melatonin from cyclodextrins-containing matrices and cyclodextrin: melatonin complexes, Int. J. Mol. Sci. 18 (2017) 1641; https://doi.org/10.3390/ijms18081641

17. M. Vlachou, K. Tragou, A. Siamidi, S. Kikionis, A. L. Chatzianagnostou, A. Mitsopoulos, E. Ioannou, V. Roussis and A. Tsotinis, Modified in vitro release of the chronobiotic hormone melatonin from matrix tablets based on the marine sulfated polysaccharide ulvan, J. Drug Deliv. Sci. Technol. 44 (2018) 41-48; https://doi.org/10.1016/j.jddst.2017.11.019 
18. M. Vlachou, S. Kikionis, A. Siamidi, K. Tragou, E. Ioannou, V. Roussis and A. Tsotinis, Modified in vitro release of melatonin loaded in nanofibrous electrospun mats incorporated into mono-layered and three-layered tablets, J. Pharm. Sci. 108 (2019) 970-976; https://doi.org/10.1016/j.xphs.2018.09.035

19. M. Vlachou, S. Kikionis, A. Siamidi, K. Tragou, S. Kapoti, E. Ioannou, V. Roussis and A. Tsotinis, Fabrication and characterization of electrospun nanofibers for the modified release of the chronobiotic hormone melatonin, Curr. Drug Deliv. 16 (2019) 79-85; https://doi.org/10.2174/15672018156 66180914095701

20. M. Vlachou, G. Stavrou, A. Siamidi, S. Flitouri, V. Ioannidou and S. Mavrokordopoulos, N-Acetylserotonin vs. melatonin. In vitro controlled release from hydrophilic matrix tablets, Lett. Drug Des. Discov. 16 (2019) 347-352; https://doi.org/10.2174/1570180815666180404125519

21. B. Girgin, O. Korkmaz, R. Yavaşer and A. A. Karagözler, Production and drug release assessment of melatonin-loaded alginate/gum arabic beads, JOTCSA 3 (2016) 205-216; https://doi.org/10.18596/ jotcsa.30880

22. O. Şanlı, N. Ay and N. Işıklan, Release characteristics of diclofenac sodium from poly (vinyl alcohol)/sodium alginate and poly (vinyl alcohol)-grafted-poly (acrylamide)/sodium alginate blend beads, Eur. J. Pharm. Biopharm. 65 (2007) 204-214; https://doi.org/10.1016/j.ejpb.2006.08.004

23. N. Pippa, N. Bouropoulos, S. Pispas, C. Demetzos and A. Papalois, Chapter 3. Hydrogels as intelligent drug delivery systems in drug delivery, Nanosystems 2019; 59-91; https://doi.org/10.1201/ 9780429490545-3

24. Pharmacopeia US, USP 29-NF24, Rockville, 2005.

25. G. Pasparakis and N. Bouropoulos, Swelling studies and in vitro release of verapamil from calcium alginate and calcium alginate-chitosan beads, Int. J. Pharm. 323 (2006) 34-42; https://doi. org/10.1016/j.ijpharm.2006.05.054

26. I. Colinet, V. Dulong, G. Mocanu, L. Picton and D. Le Cerf, New amphiphilic and pH-sensitive hydrogel for controlled release of a model poorly water-soluble drug, Eur. J. Pharm. Biopharm. 73 (2009) 345-350; https://doi.org/10.1016/j.ejpb.2009.07.008

27. N. Pippa, T. Sentoukas, S. Pispas, C. Demetzos, A. Papalois and N. Bouropoulos, pH-responsive polymeric nanoassemblies encapsulated into alginate beads: morphological characterization and swelling studies, J. Pol. Res. 25 (2018) 117; https://doi.org/10.1007/s10965-018-1519-1

28. J. Siepmann and N. A. Peppas, Modeling of drug release from delivery systems based on hydroxypropyl methylcellulose (HPMC), Adv. Drug Deliv. Rev. 48 (2001) 139-57; https://doi.org/10.1016/S0169409X(01)00112-0

29. P. L. Ritger and N. A. Peppas, A simple equation for description of solute release II. Fickian and anomalous release from swellable devices, J. Control. Release 5 (1987) 37-42; https://doi. org/10.1016/0168-3659(87)90035-6

30. N. H. Anderson, M. Bauer, N. Boussac, P. R. Khan-Malek, P. Munden and M. Sardaro, An evaluation of fit factors and dissolution efficiency for the comparison of in vitro dissolution profiles, $J$. Pharm. Biomed. Anal. 17 (1998) 811-822; https://doi.org/10.1016/s0731-7085(98)00011-9

31. J. L. Shamshina, G. Gurau, L. E. Block, L. K. Hansen, C. Dingee, A. Walters and R. D. Rogers, Chitin-calcium alginate composite fibers for wound care dressings spun from ionic liquid solution, $J$. Mater. Chem. B 2 (2014) 3924; http://dx.doi.org/10.1039/C4TB00329B

32. S. Soni, A. Verma and V. Ram, Evaluation of chitosan-hydroxy propyl methyl cellulose as a single unit hydrodynamically balanced sustained release matrices for stomach specific delivery of piroxicam, MOJ Bioequiv. 2 (2016) 14; http://dx.doi.org/10.4172/0975-0851.C1.025

33. T. H. C. Salles, C. B. Lombello and M. A. d'Ávila, Electrospinning of gelatin/poly (vinyl pyrrolidone) blends from water/acetic acid solutions, Materials Research 18 (2015) 509-518; http://dx.doi. org/10.1590/1516-1439.310114

34. Y. Listiohadi, J. A. Hourigan, R. W. Sleigh and R. J. Steele, Thermal analysis of amorphous lactose and $\alpha$-lactose monohydrate, Dairy Sci. Technol. 89 (2009) 43-67; https://doi.org/10.1051/dst:2008027 
35. A. S. Hoffman Hydrogels for biomedical applications, Adv. Drug Deliv. Rev. 43 (2002) 3-12; https:// doi.org/10.1016/j.addr.2012.09.010

36. S. P. Chaudhari and R. H. Dave, Investigating the effect of molecular weight of polyvinylpyrrolidone and hydroxypropyl methyl cellulose as potential antiprecipitants on supersaturated drug solutions and formulations using weakly acidic drug: indomethacin, IJPSR 7 (2016) 3931-3948; https://doi.org/10.13040/IJPSR.0975-8232.7(10).3931-48

37. A. Körner, L. Piculell, F. Iselau, B. Wittgren and A. Larsson, Influence of different polymer types on the overall release mechanism in hydrophilic matrix tablets, Molecules 14 (2009) 2699-2716; https://doi.org/10.3390/molecules14082699

38. M. Vlachou, A. Siamidi and E. Geraniou, Modified release of furosemide from Eudragits ${ }^{\circledR}$ and poly(ethylene oxide)-based matrices and dry-coated tablets, Acta Pharm. 70 (2020) 49-61; https:// doi.org/10.2478/acph-2020-0010 